\title{
Effect Times Number of Spray and Concentration of Foliar Fertilizer (PIO20) in Growth and Yield of Cucumber Variety Jamila Planted in Plastic Houses Conditions
}

\author{
Heba A. Hussein ${ }^{\text {a }}$ \\ Hakeem Sh. Atallah ${ }^{\text {b }}$ \\ Shawqi N. Yousif \\ ${ }^{a}$ Al-Musaib Technical College \\ ${ }^{b, c}$ Agriculture Directorate Babel \\ b Hakeem9900@yahoo.com \\ ${ }^{\mathrm{c}}$ Shawqiiraq@gmail.com
}

Submission date:- 25/10/2017

Acceptance date:- 71/1/2018

Publication date:- 8/8/2018

Keywords: Foliar fertilizer, Cucurbitaceae, Spray, Plastic houses.

\begin{abstract}
The experiment was conducted during season of 2016 in plastic houses at Azawia- Babylon to study effect times number of spray (two times ، three times ) with four levels of spray by foliar nutrition PIO20 (0، 1.5 ، 2 ، 2.5 ml. liter $^{-1}$ ) in cucumber plant c.v. jamila. The experiment was conducted of factorial in design using (C.R.D) with three replicates. Results showed the treatment spray of three times significantly on the treatment spray two times when imported plant length rate (291.4) cm ,the number of leaves (36.63) leaf and dry weight of the shoot (25.76) $\mathrm{gm}$, fruit long (17.98) $\mathrm{cm}$, fruit weight (109.27) gm and the number of fruits (11.80) fruit.plant ${ }^{-1}$ and the one plant yield $(1.294) \mathrm{kg}$. the results also showed all the treatment of spray significantly in vegetative growth and fruiting characteristics as compared with control treatment. the results of the interaction the significant superiority of the treatment spray of three times on the level $2 \mathrm{ml}^{\text {. liter }}{ }^{-1}$ plant length rate $(311.3) \mathrm{cm}$, the number of leaves $(40.71)$ leaf and dry weight of the shoot (32.09) gm, fruit long (19.34) cm , fruit weight (116.06) gm and the number of fruits (12.97) fruit.plant ${ }^{-1}$ and the one plant yield (1.506) $\mathrm{kg}$.
\end{abstract}

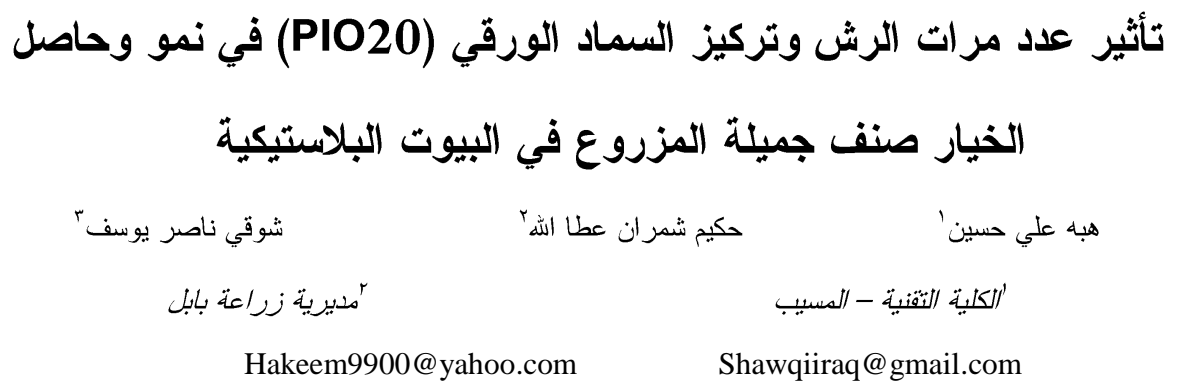

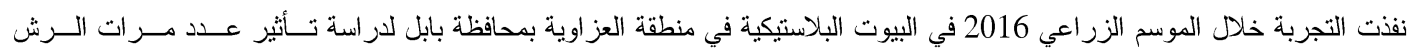

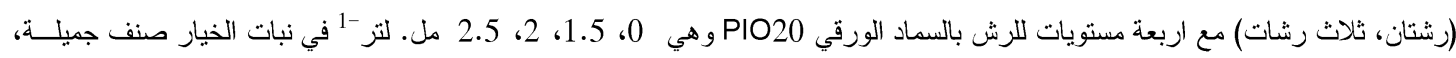

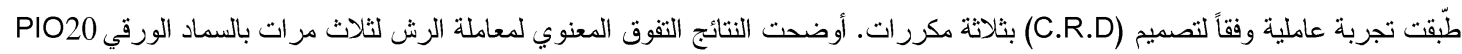

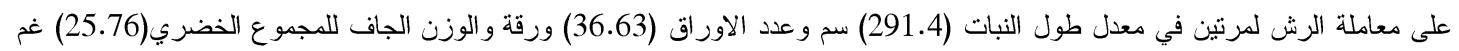

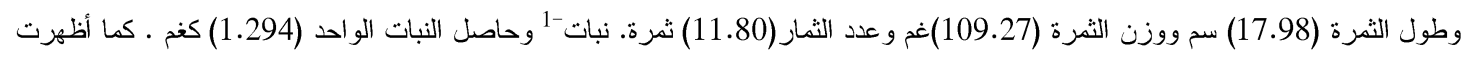

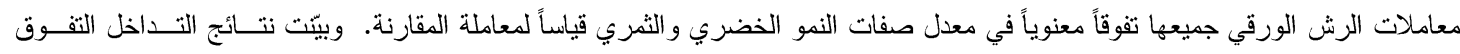

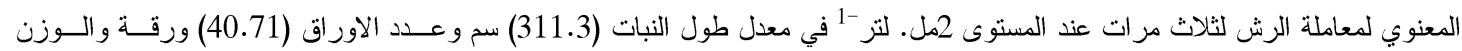

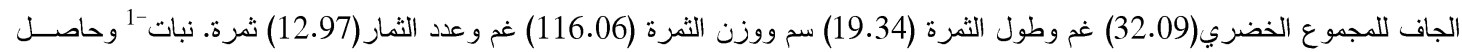
النبات الو احد (1.506) كغم. 
يعد الخيار .Cucumis sativus L من محاصيل الخضر الصيفية الثائعة والذي ينتمي الى العائلة القرعية Cucurbitaceae التي تضم 90

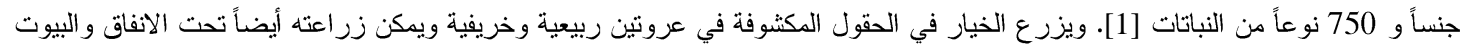

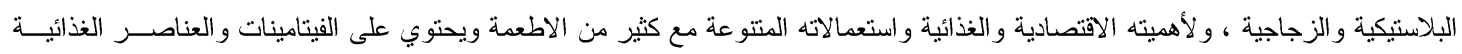

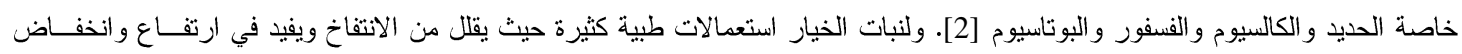

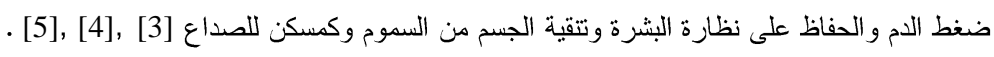

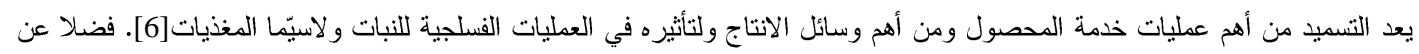

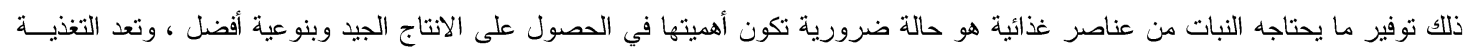

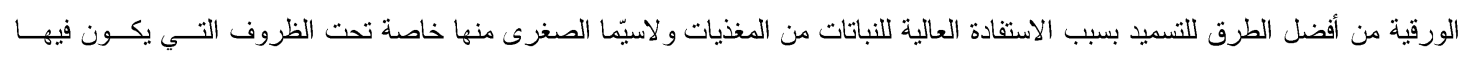

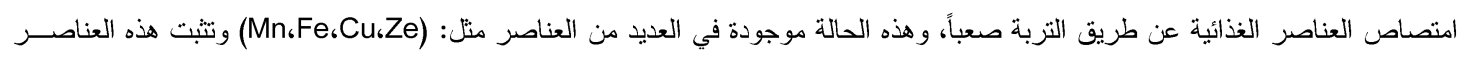

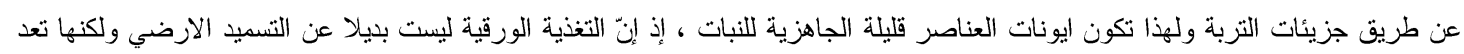

مكملة له [7].

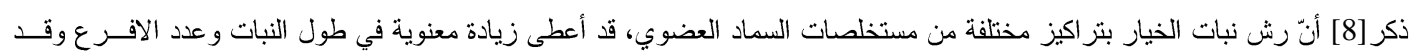

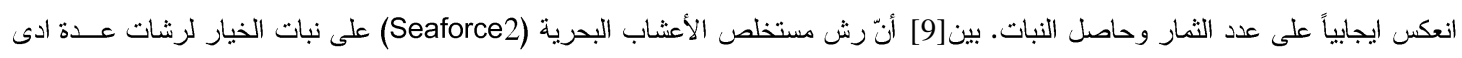

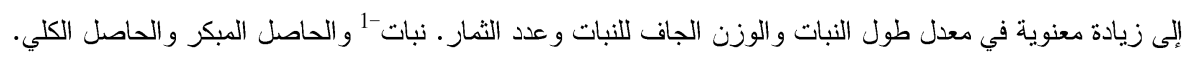

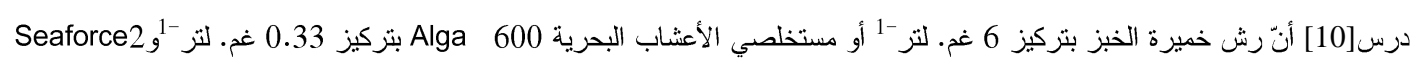

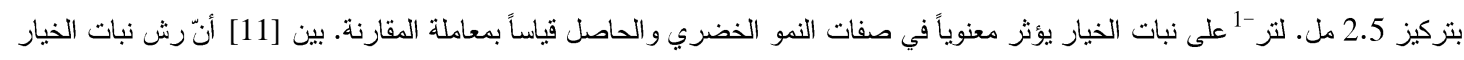

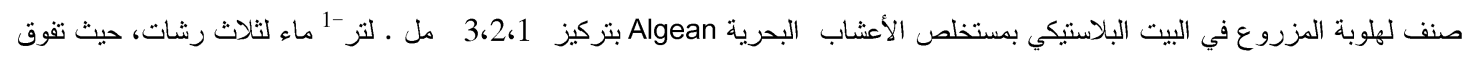

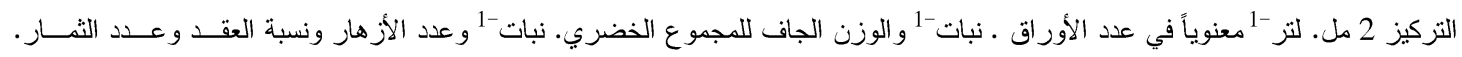
نبات -1 و الحاصل الكلي. الشار[21] أنّ رش مستخلصات النباتات البحرية Algreen, Algamax على نباتات البطيخ أدّى الى التبكير في موعد النضج وزيادة عدد الثمار . نبات -1 و الحاصل الكلي. وجد حسين و [13] أنّ رش سماد (فول سبراي) بنركيز من الخيار هما: Krass Karima، عند الأزهار و على حقبات 10 أيام بين رشة وأخرى المزروعة في البيت البلاستيكي، إذّ أعطى التركيز 2.5

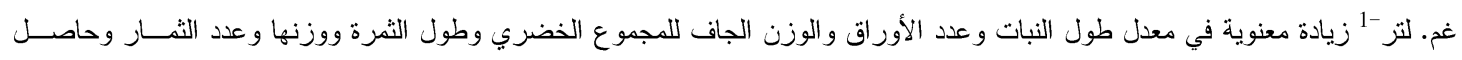

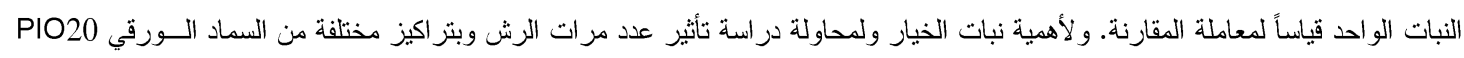
في نمو النبات هدفت الدراسة لمعرفة تأثثر الرش بالسماد الثية نبات الورقي PIO20 في نمو وحاصل الخيار المزروع في البيوت البلاستيكي.

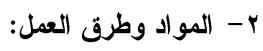

أجزيت التجربة خلال الموسم الزراعي لعام 2016م في أحد البيوت البلاستيكية في منطقة العز اوية شمال مدينة الحلة، شملت التجربة ثمان

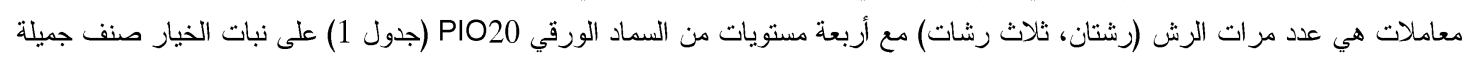

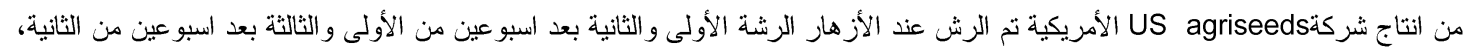

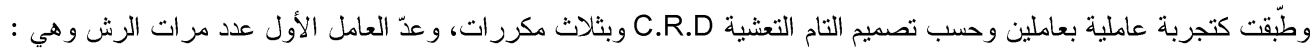

العامل الثاني مستويات الرش من السماد الورقي PIO20 من انتاج شركة اوميكس- المملكة المتحدة (جدول1) ويشمل:

$$
\begin{aligned}
& 1 \text { - من دون رش (مقارنة) . } \\
& 2 \text { - } 2.5 \text { مل. لتز -1. } \\
& 3 \\
& 4 \text { - } 4.5 \text { مل. لتر -1. }
\end{aligned}
$$


PIO20 Pدول (1) مكونات السماد الورقي

\begin{tabular}{|c|c|c|c|c|c|c|c|c|}
\hline $\mathrm{Zn}$ & $\mathrm{Mn}$ & $\mathrm{Fe}$ & $\mathrm{Cu}$ & $\mathrm{B}$ & $\mathrm{Mgo}$ & $\mathrm{K}_{2} \mathrm{O}$ & $\mathrm{P}_{2} \mathrm{O}_{5}$ & $\mathrm{~N}$ \\
\hline$\% 0.073$ & $\% 0.073$ & $\% 1.46$ & $\% 0.073$ & $\% 0.029$ & $\% 1.5$ & $\% 20$ & $\% 20$ & $\% 20$ \\
\hline
\end{tabular}

وأخذت عينات عشو ائية من تربة البيت البلاستيكي على عمق (0 - 30 سم) وتم تحليل التربة في مختبر البحوث الزراعية- التابع لمديرية

زر اعة بابل جدول (2).

جدول (2) يوضح بعض الصفات الفيزيائية والكيميائية لتربة البيث البلاستيكي

\begin{tabular}{|c|c|c|c|c|c|c|c|c|c|}
\hline \multirow{3}{*}{ النسجة } & \multicolumn{9}{|c|}{ الصفات } \\
\hline & غرين & رمل & طين & \multirow[t]{2}{*}{ ppm K } & \multirow[t]{2}{*}{ ppm P } & \multirow[t]{2}{*}{ ppm N } & \multirow{2}{*}{ العضوية المادة } & \multirow{2}{*}{$\begin{array}{l}\text { / Ece } \\
\text { ds.m }{ }^{-1}\end{array}$} & \multirow[t]{2}{*}{$\mathrm{pH}$} \\
\hline & \multicolumn{3}{|c|}{$\%$} & & & & & & \\
\hline رزيجية & 15.80 & 80.20 & 4 & 360 & 8.7 & 52.5 & 1.13 & 3.7 & 7.4 \\
\hline
\end{tabular}

حرثت تربة البيت البلاستيكي وتم تتعيمها وقسّت إلى مساطب وثم قسّّت إلى وحدات تجريبية بلغــت (24) وحسـدة تجريييـة بطــول 2 م

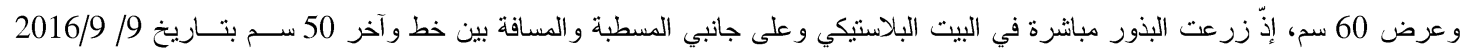

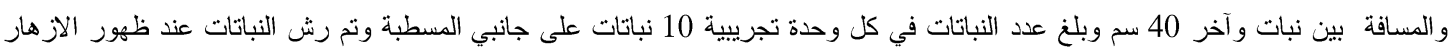

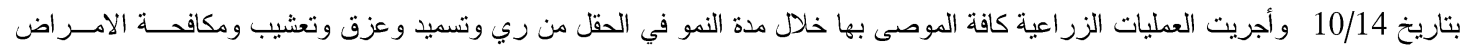
والحشرات بصورة متماثلة للوحدات التجريبية جميعها وبدأ جني الثمار بتاريخ 10/25 واستمر لغاية 2016/12/11.

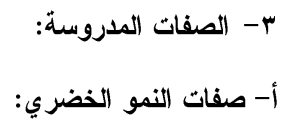

1. طول النبات(سم): تم قياسه في نهاية الموسم بوساطة شريط قياس واخذ معدل طول خمسة نباتات من كل وحدة تجرييية ولكل مكرر. 2. عدد الأوراق. نبات -1': تم حساب معدل عدد الأوراق في نهاية الموسم لخمسة نباتات من كل وحدة تجرييية ولكل مكرر. 3. الوزن الجاف للمجموع الخضري(غم): تم حساب هذه الصفة في نهاية الموسم بعد قلع خمسة نباتات وغسلها وتجفيفها في فرن كهربائي عند درجة 70 م لمدة 72 ساعة لحين ثبات الوزن . ب- صفات النمو الثري: 1. معدل طول الثمرة (سم): تم حساب معدل طول الثمرة بو اسطة المسطرة الاعتيادية والثلاث ثمار. 2. معدل عدد الثمار . نبات-1: تم حساب هذه الصفة من الجنيات جميعها طو ال مدة الجني لكل وحدة تجريبية للمكررات جميعها ثم قســم العـدد الكلي للثمار في كل وحدة تجريبية على عدد النباتات في تلك الوحدة. 3. متوسط وزن الثمرة (غم): قدر على اساس الحاصل الكلي لكل وحدة تجريبية مقسوماً على عدد الثمار الكلي لتلك الوحدة التجريبيــة طــوال الموسم.

4. حاصل النبات الواحد (كفر): قدر على اساس حاصل كل وحدة تجريبية طو ال موسم النمو مقسوماً على عدد النباتات في الوحدة التجريبية. وحللت النتائج على وفق التصميم المتبع، واستعمل اختبار اقل فرق معنوي L.S.D لمقارنة المتوسطات عند مســتوى احتـــال[14] 0.05

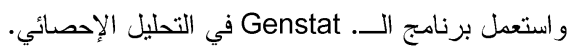


تثنير النتائج في الجدول (3) إلى أنّ معاملة الرش لنثلاث مرات بالسماد الورقي PIO20 قد تنوقت معنوياً على معاملة الرش

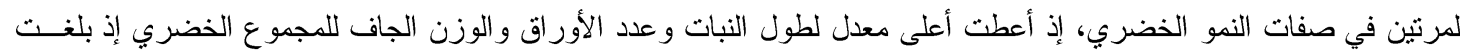

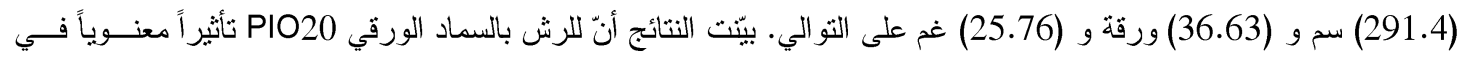

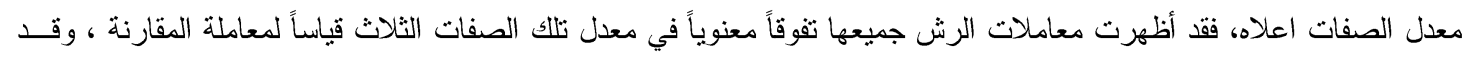

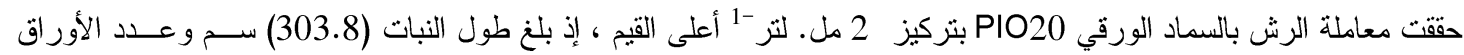

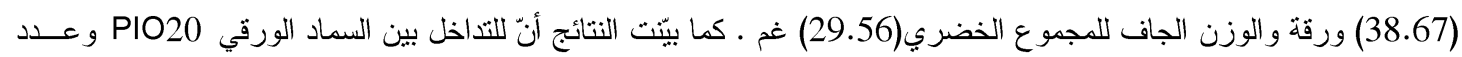

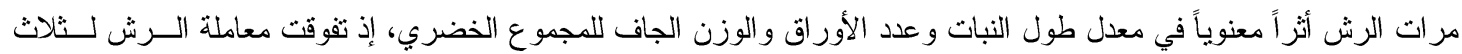

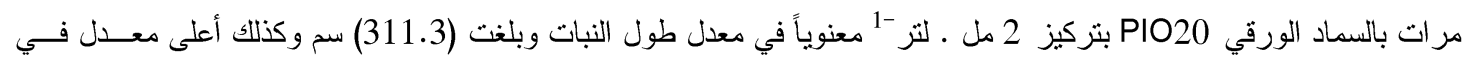

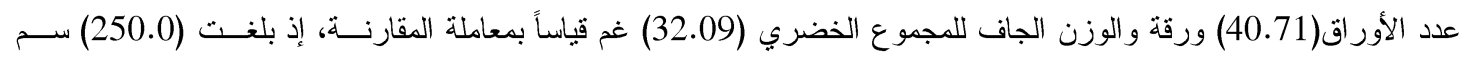

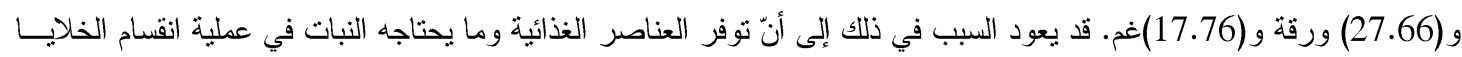

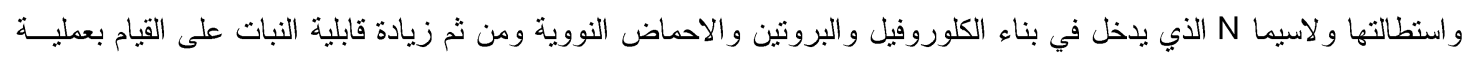

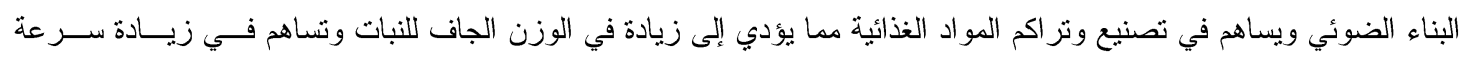

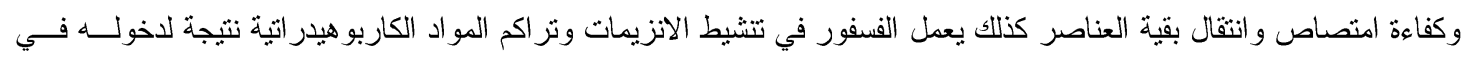

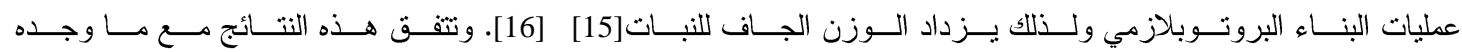
[18] [17] [13] جدول (3) تأثير عدد مرات الرش وبمستويات مختلفة من السماد الورقي PIO20 و التداخل بينهما في صفات النمو الخضري لصنف الخيار جميلة.

\begin{tabular}{|c|c|c|c|c|c|}
\hline \multicolumn{6}{|c|}{ طول النبات سم } \\
\hline الرشدات عدد & مل.لتر-1 2.5 & مل.لتر-1 2 & 1.5مل.لتر 1.5 & 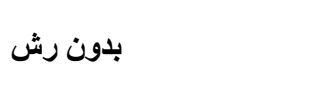 & \\
\hline 272.6 & 280.8 & 296.2 & 263.3 & 250.0 & رشتان \\
\hline 291.4 & 290.7 & 311.3 & 288.0 & 275.7 & ت ثلاث رشات \\
\hline & 285.8 & 303.8 & 275.7 & 262.8 & معدل التركيز \\
\hline & للتداخل = 11.19 & & لتركيز = 7.91 & لعدد الرشات = 5.60 & L.S.D 0.05 \\
\hline \multicolumn{6}{|c|}{ عدد الاوراق. نبات-1- } \\
\hline 33.23 & 34.66 & 36.62 & 33.98 & 27.66 & رشتّان \\
\hline 36.63 & 37.61 & 40.71 & 35.78 & 42.32 & ثلاث رشات \\
\hline & 36.16 & 38.67 & 34.88 & 30.04 & معدل التركيز \\
\hline & للتـاخل = 2.70 & & لتركيز =1.91 & لعدد الرشات = 1.35 & L.S.D 0.05 \\
\hline \multicolumn{6}{|c|}{ الوزن الجاف للمجموع الخضري غر } \\
\hline 22.61 & 24.56 & 27.02 & 21.00 & 17.76 & رشتان \\
\hline 25.76 & 27.09 & 32.09 & 23.85 & 20.02 & ثلاث رشات \\
\hline & 25.87 & 29.56 & 22.43 & 18.89 & معدل التركيز \\
\hline & للتداخل = 2.21 & & لتركيز = 1.56 & لعدد الرشات =1.11 & L.S.D 0.05 \\
\hline
\end{tabular}




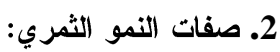

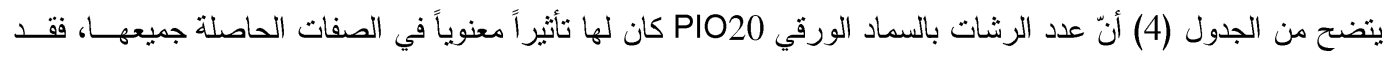

تفوقت معاملة الرش لثثلاث مرات معنوياً على معاملة الرش مرثين في معدل طول الثمرة ووزن الثمرة وعدد الثمار وحاصل النبات

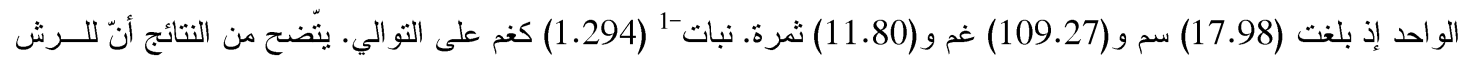

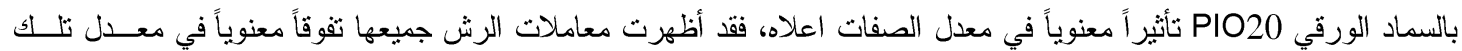

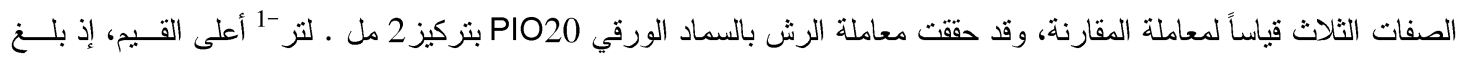

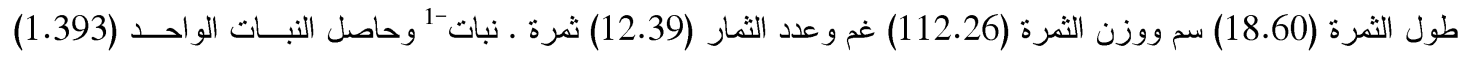

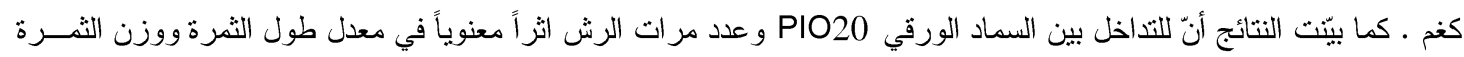
و عدد الثمار وحاصل النبات الو احد، حبث تفوقت معاملة الرش لثثلاث مرات بالسماد الورقي

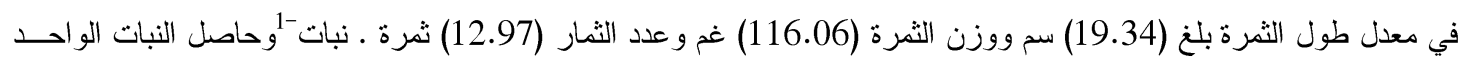

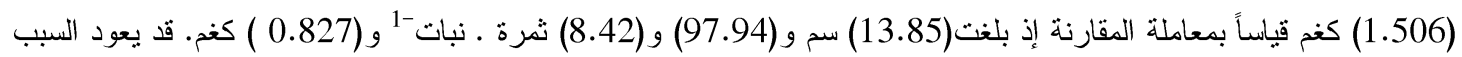

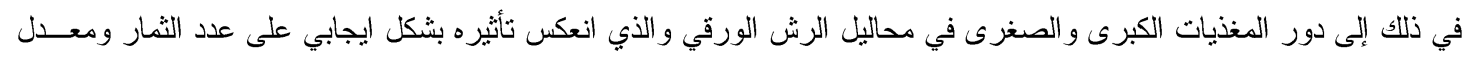

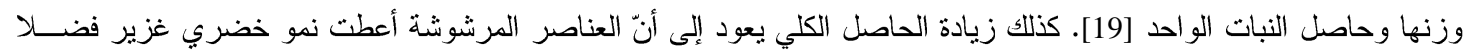
عن دور العناصر في نثاط الانزيمات وتتظيم الفعاليات الحيوية وهذا ينعكس على تطور نمو الثمرة وزيادة وزنها وبالتـالي زيــادة

الحاصل وتتفق هذه النتائج مع [16].

ويستتتج من هذه الدر اسة أنّ معاملة الرش لثنلاث مرات اظهرت تفوقاً معنوياً على معاملة الرش مـــثنين فـي صــفات النمــو

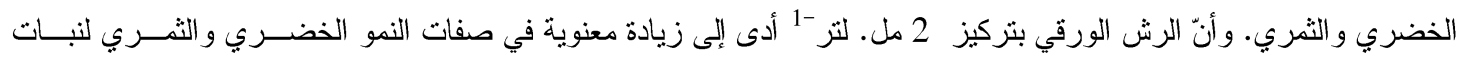
الخيار • وجد أنّ معاملة الرش لثلاث مر ات بالسماد الورقي اثناء موسم الزر اعة.

جدول (4) تأثير عدد مرات الرش وبمستويات مختلفة من السماد الورقيPIO20 والتداخل بينهما في صفات النمو الثمري لصنف الخيار جميلة .

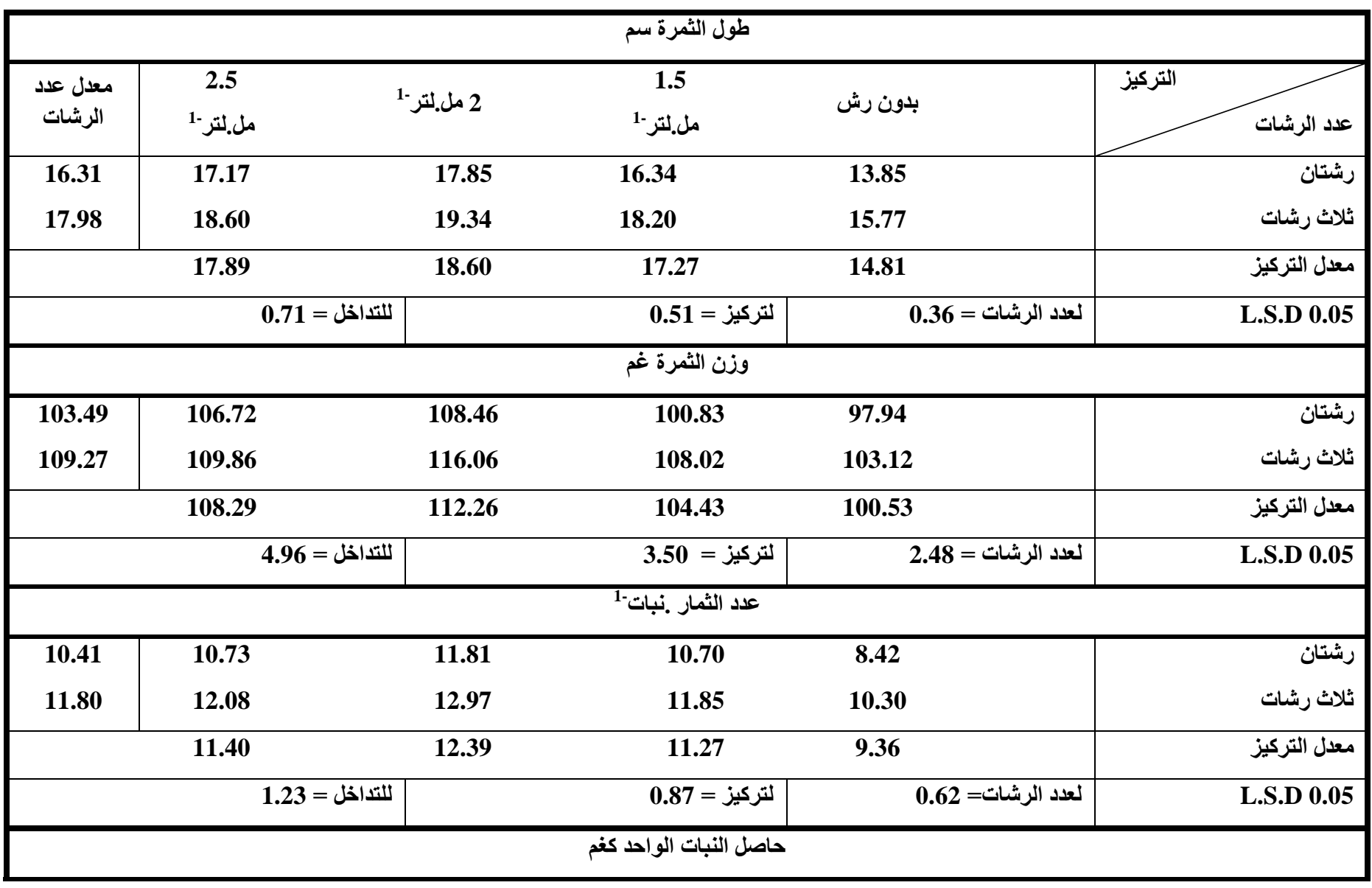




\begin{tabular}{|c|c|c|c|c|c|}
\hline 1.083 & 1.146 & 1.281 & 1.080 & 0.827 & رشتان \\
\hline 1.294 & 1.327 & 1.506 & 1.280 & 1.062 & ثثلاث رشات \\
\hline & 1.327 & 1.393 & 1.180 & 0.944 & معدل التركيز \\
\hline & للتداخل = 0.16 & & $0.11=$ لتركيز & لعدد الرشات = 0.08 & L.S.D 0.05 \\
\hline
\end{tabular}

\section{CONFLICT OF INTERESTS}

\section{There are no conflicts of interest.}

\section{المصادر}

[1] الركابي، فاخر محمد وعبد الجبار جاسم الشثعل. انتاج الخضر . مؤسسة المعاهد الفنية. وزارة التعليم العالي والبحث العلمي. العراق .ص.

[2] حمادي، فاضل مصلح و عبد الجبار جاسم المشعل. انتاج الخضر. مطابع وزارة التعليم العالي والبحث العلمي. جامعة بغداد. العراق.1987.

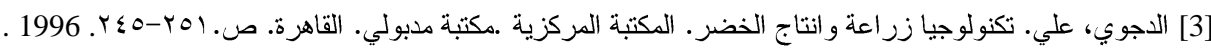

[4] T.Sumathi, V. Ponnuswami and B.S. Selvi. Anatomical changes of cucumber (Cucumis sativus L.) leaves and roots as influenced by shade and fertigation. Res.J. of Agric and Biol. Sci.4 (6): 630-638. 2008.

[5] K.Waseem, Q. M. Kamran and M. S. Jilani. Effect of different nitrogen levels on growth and yield of cucumber (Cucumis sativus L.). J. Agr. Res. 46 (3): 259-266. 2008.

$$
\begin{aligned}
& \text { [6] ابو ضاحي، يوسف محمد ومؤيد احمد اليونس. دليل تغذية النبات ـ وزارة التعليم العالي والبحث العلمي. جامعة بغداد. 1911. } \\
& \text { [7] الجواري،عبد الرحمن خماس سهيل. تأثثر الرش بمغذيات مختلفة في نمو وحاصل الفلفل الحلو. رسالة ماجستير. كلية }
\end{aligned}
$$

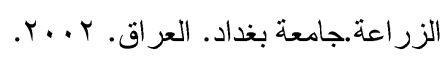

[8] Y.A. Bayoumi, and Y.M.Hafiz. Effect of organic fertilizers com-bined with benzo $(1,2,3)$ thiadiazole -7- carbothioic acid s-methyl-ester(BTH) on the cucumber powdery mildew and the yield production. Acta. Biol. Szegediensis .50(3-4):131-136. 2006.

$$
\text { [9] محمد، عبد الرحيم سلطان. تأثير التشميد النتروجيني و الرش بمستخلصات الأعثاب البحرية في النمو والحاصل لنبات الخيار. }
$$

[10] T.Z. Sarhan, S.T. Ali and S.M. Rasheed. Effect of bread yeast application and seaweed extract on cucumber (Cucumis sativus L.) plant in growth , and fruit quality .Mesopotamia.J. of Agric.39(2):2634. 2011.

$$
\begin{aligned}
& \text { [11] عبيد، عبد الرحيم عاصي و حميد صالح حماد و صبيح عبد الوهاب عنجل. تــأثير الــرش الــورقي للأســـدة الفوسـفاتية }
\end{aligned}
$$

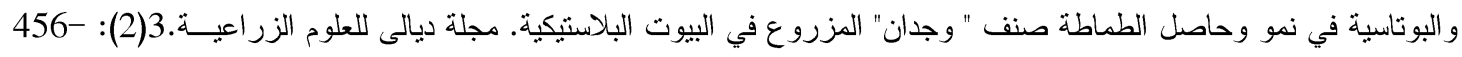

$$
\begin{aligned}
& 2011.451 \\
& \text { [12] اللبلة، وليد بدر الدين محمود. تأثير التسميد باليوريا والرش بمستخلصي النباتات البحرية الجايمس والالجــرين فـي النمــو }
\end{aligned}
$$

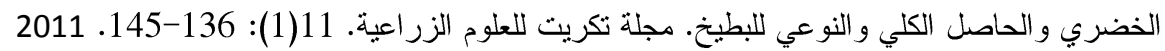

$$
\begin{aligned}
& \text { [13] حسين، هبه علي وحكيم شمران عطالله. نأثثر الرش بالسماد الورقي فول سبراي في نمو وحاصل هجينين من الخيار }
\end{aligned}
$$

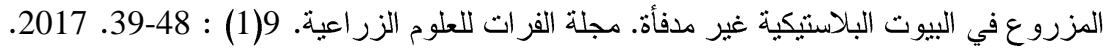

$$
\begin{aligned}
& \text { [14] الساهوكي، مدحت مجيد وكريمة محمد و هيب .تطبيقات في تصميم وتحليل التجارب. جامعة بغــداد. وزارة التعلــيم والبحــث } \\
& \text { العلمي. العراق.1990 }
\end{aligned}
$$

[15] K.S.Abdul. An investigation of the inter action .between mineral nutrition, light and temperature and on growth and development of tomato plants.Zanco.4:83-96. 1978. 
[16] حسين، وفاء علي وفاخر حمد الركابي. استجابة نبات الخيار Cucumis sativus L. للرش بمستخلص الثوم وجذور عرق

السوس و اليوريا في صفات النمو الخضري وحاصل النبات. مجلة العلوم الزر اعية العر اقية. 37(4): 38-33 .2006

[17] D. A.Morreno, G. Villora; L. Romero. Variations in fruit micronutrient content associated with fertilization of cucumber with macronutrients. Scientia Horticulture (97): 121-127. 2003.

[18]الرييعي، باقر جلاب هادي وجابر جاسم طليثة وحكم كريم ادويني. تأثثر المغذيات الورقية وطريقة الزر اعة في نمو وحاصل

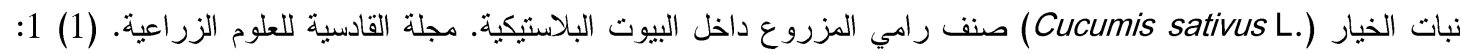

.2011. 51-42

[19]حسن، احمد عبد المنعم. القرعيات، البطيخ، القاوون (الكانتالوب)، الثمام، الخيار، الكوسة. الطبعة الاولى. الدار العربية للنشر

والتوزيع. جمهورية مصر العربية. 2001 